\title{
Measuring women's work: methodological and conceptual issues in Latin America
}

\section{Magdalena Leon}

Women's participation in the labour force differs from men's in several important ways, and when expressed statistically it tends to be underestimated. What are these differences in labour force participation, and why does this distortion occur?

The sexual division of labour in society allows men to enjoy a considerable degree of homogeneity in their labour force participation over the whole of their working life. Generally speaking, they remain in the labour force from the day they enter it to the day they retire; their labour force participation is relatively unaffected by life cycle phases, their level of education, family situation (whether they are married, separated, divorced or single; whether they have children or not, etc), their place of residence (whether urban or rural). In contrast, women's participation is discontinuous and fragmented; they enter and leave the labour force several times during their life span; their pattern of participation is associated with changes in their life cycle, with their civil status, the number of children they bear and rear, etc. Generally speaking, the women who have the most regular economic activity profile are those who are highly educated, are not married or have no children, and are in certain occupations (often those which are in some degree an extension of women's domestic role - teaching, nursing, etc). This then is the panorama that the sexual division of labour produces, yet even a cursory look at censuses, at least in Latin America, shows that their design takes very little account of the effects of this social organisation of activity.

\section{Census: problems related to measurement}

Until the 1930s, economic activity, or lack of it, was captured by asking questions about the paid work people undertook. Enumerators tried to take into account either the habitual status of a person (eg landlord), or their occupational status (eg carpenter or architect), or their habitual means of livelihood (eg fisherman, farmer), whether or not the person was actually exercising the occupation, profession or skill.
Respondents were not asked what they had been doing during a given period before the census, but merely what their potential for work was. By this means it was possible to capture a good deal of economic activity which later censuses have tended to ignore, and thus women's economic participation is generally registered as much lower in censuses after the 1930s than before.

There were, however, a number of difficulties with the questions asked: census enumerators were not given clear instructions as to how to classify respondents, nor was any minimum time specified, nor, as we have noted, was any reference period established.

Since the 1950 s the form of questions has changed so as to try to resolve these difficulties. Information is now sought in terms of actual occupation, or labour force participation, rather than in terms of potential participation. There is a specific reference period, usually rather close to the time of the census; the questions as to activity tend to presuppose a relationship with the labour market which is expressed in the census category of 'type or condition of work'; there is a minimum period of time in which the activity is undertaken. In other words there is a somewhat stricter definition of what constitutes economic activity, and as a consequence a good deal of women's work is missed out. Both approaches classified people in terms of their economic characteristics, but the first emphasises their relatively permanent status and implicitly assumes little occupational mobility; the second is based on the occupational situation of the population at a specific period of time, and implicitly accepts a certain degree of mobility.

In this second approach (ie labour force participation rather than potential for paid work) the population is divided into those within the economically active age, and those outside it. The former category is further sub-divided into two: those who are economically active and those who are economically inactive. The economically active are further subdivided into those 
who are in paid work, those who are unpaid family workers, and those who are unemployed but are actively seeking work. Economically inactive persons - students, pensioners, housewives - receive no wage and are not in the labour market.

\section{Problems with Census Methodology}

There are two main problems associated with this type of data collection: how to measure the activity as defined by the census; and the definitions themselves, ie conceptual problems, particularly with the principal concept, that of work. Both sets of problems arise from the assumption that it is possible to define type or conditions of work without taking into account the type of economy within which the activity is located. In fact the concept of economically active population is derived from an advanced market economy in which market conditions allow for the majority of workers to be in paid employment, in stable jobs with standardised hours of work; and in which there is a generalised concept of a legal working day and more or less regularised (and monitored) working conditions and rates of pay. In underdeveloped countries, however, these conditions either do not exist, or are not widespead, because dependent capitalist development allows for, or even produces, considerable economic heterogeneity.

Quite apart from this general problem of the type of economy, there are a number of other measurement problems and difficulties. Let us look at censuses in Latin America after the 1970 s to see whether the census categories in fact measure what they set out to measure, as well as to establish the reliability - that is, the consistency of measurement - and thus comparability of census data from period to period, and from country to country.

I shall focus on three points: i) the ways in which information about labour force activity is collected; ii) the reference period; iii) the minimum time requirement used for defining activity.

\section{Labour force activity}

The majority of Latin American censuses use only one question to establish activity or inactivity; some use two, others use as many as six, others do not ask any questions at all but still have this as a census category. When a question is asked it generally takes the form of 'What did you do in week X?' (giving the dates), or 'Of the following activities, which do you engage in?' (a list of alternatives then being given). Problems of comparability do not end here because different countries list different activities; again, some start with those which define inactivity and others with those which define activity. The matter is further complicated by variations in the way the stimulus (ie the alternatives) is given to respondents. In some cases the respondent is given the whole list of alternatives and has to select one (and only one), while in others the interviewer stops reading out the list when the respondent indicates participation in one activity.

There are a number of problems with both methods but I shall only discuss two. Firstly, of the two forms of presenting the stimulus, the one which gives inactivity first is more prejudicial to getting information about women's work. This is because many women respond to the activity word - housewife, student - despite the fact that they may be engaged in other activities as well. Secondly, only one option is open for selection: that is, one is either active or inactive. This clearly leads to the underestimation of a great deal of what is typically women's work for two reasons: women may undertake a number of activities (washing clothes, looking after children, making food) either simultaneously, or consecutively, but for brief periods of time. Furthermore, cultural practices make it highly likely that a large number of women will respond to the classification 'housewife' despite the fact that they are in fact gainfully employed in other activities, whether these are regular but part-time, or temporary.

\section{Period of reference}

Since the 1950s, throughout Latin America, one week has been standardised as the time reference period, with the exception of Haiti which uses six months, and Jamaica, Barbados and Trinidad and Tobago which use two time periods, one week and one year. But even where one week is the standard, comparability is still a problem because the week selected is identified in two different ways: - as the week prior to the interview; - as a given week (ie dates given).

This gives rise to a number of difficulties: firstly, if the census takes more than a day to complete (as is the case in certain isolated regions in many Latin American countries), the week prior to the interview may well vary from area to area. Secondly, the seasonality of activities (particularly in agriculture but also in the informal sector) is ignored - and of course, agricultural peaks vary from area to area as well. This is particularly disadvantageous as far as capturing women's work is concerned since much of women's paid labour occurs during harvest or planting, or when post-harvest processing is carried out. Thirdly, the concept of a given unit of time is problematic with populations which are either illiterate or semi-literate. We do not often know what the phrase the week before this' actually means to respondents. In the Andean world, this problem is particularly acute because their definition of time is quite different from ours. 


\section{Minimum period requirement}

There is little agreement in Latin American censuses as to what minimum period of activity constitutes active economic participation except in the case of unpaid family workers, who have to have worked one-third of the normal working day (ie 15 hours per week) to be eligible for this status. In other words, there is a considerable problem in defining the economically active population. In six Latin American countries no minimum time is stipulated; in nine more or less fulltime work appears to be the requirement because at least four days work totalling $\mathbf{3 5}$ hours is required; in one, the referent would appear to be part-time because 15 hours a week is stipulated, and in seven a period of between one and 18 hours per week is laid down - ie what we might designate temporary work.

Difficulties with this question do not end here for there are contradictions in the way instructions are given to interviewers: in some cases the instructions are included on the questionnaire form, in others they are kept in a separate manual. In some cases the instructions given in the questionnaire contradict those found in the manual. For example, in Colombia where economic activity is measured by one hour's paid work during the reference week, unpaid family workers need to work 15 hours to be characterised as such. As a result only one per cent of unpaid family workers were registered in the 1973 census.

This of course leads to an underestimation not only of women's work in general but particularly of rural women's participation, since the great bulk of their work is unpaid. A solution we have suggested to this problem is that no minimum time should be included either in the form of a question or in the instruction to the interviewer, but rather that respondents should be asked to estimate the actual time spent working, either hours in a week, or weeks in a month, or months in a year.

\section{Household Surveys}

Since 1950 the UN has suggested that underdeveloped countries should adopt a system of data collection based on household surveys and that data should be collected regularly, should allow for comparison between countries as well as from one period to another, and should also be multi-purpose. The US Bureau of the Census, in collaboration with USAID, developed a model household survey (Atlantida) which includes information on how to: select the themes for investigation; select the sample households; design a questionnaire; prepare an instruction manual for interviews; process and tabulate the dat a collected. A scheme for analysing the data is also provided. This package ensures that household surveys will be comparable from one period to another, and from one country to another.
As far as the economic characteristics of the population are concerned, it adopts the same conceptual approach as the labour force approach mentioned earlier. There are some technical differences, however; for example, instead of only one question directed to eliciting information about activity, there is a series of questions which try to ascertain the degree of activity or inactivity, and to collect information about other variables, eg the time dedicated to the activity in hours per week; any predisposition to work longer; and, in the case of inactivity, to understanding why the person is inactive.

As a result of the range of information which can be gained from these surveys, they are more reliable in general as to labour force activity, particularly in the case of women. Why should this be so? In part because design of the sequence of questions allows for more information to be gathered on women's labour force activity and on those people whose work profiles are discontinuous, ie who undertake sporadic, part-time or temporary work. It also enables the interviewer to establish the degree of unpaid family work undertaken. It is thus a better instrument to capture underemployment, unemployment, multiple employment, etc, and to record much of the sort of employment provided by the informal sector. Characteristically, much of this type of work is carried out by women.

Another advantage of household surveys is that unlike census enumerators, survey interviewers are given specialised training and are paid. Thus they can be alerted to the range of prejudices against women's economic participation and to the need for considerable caution in accepting such categorisations as 'I am only a housewife'.

Logically, one would expect any comparison of census data and household survey data to show considerable differences in the measurement of the same phenomenon; however, there are few examples to demonstrate this, given that household surveys are rarely carried out at the same time as census surveys, in the same region and investigate the same phenomenon. However, I can give three examples from Latin America, all focusing on economic activity:

Panama - comparing the economic activity of all age cohorts (15-19,20-24, etc) as given in the census and in household surveys, the range of difference for female activity is never less than 5 per cent; generally it is about 10 per cent and reaches 43 per cent at the uppermost end of the variance.

São Paulo, Brazil - comparing census with survey data the underestimation of women's economic participation varies from 14 per cent to 39 per cent; for men the figures are 2 per cent to 6 per cent. 
Bolivia - a comparison of the two data sets shows that between 33 per cent and 48 per cent more women are active than shown in the census.

\section{Improving the data}

Given these sets of figures and the problems that I have discussed, the question must be, what can be done to improve the accuracy of the census? The solution for the census is not to collect more data but to collect better data. But how is this to be achieved? Basically, the first essential is to ask a battery of questions about one area of interest such as labour force participation, economic activity, etc. Secondly, when analysing the data, the basic unit should not be the individual, or aggregations of individuals, but the household. In other words, the domestic unit should be the basis of analysis.

As for household surveys, we would recommend that the data collected be expanded, and divided into two types: that which is always collected and that which is occasionally collected. With this additional survey data, it should be possible not merely to show what women do, but also to explain why they do it, the form in which they do it, and the contribution this makes to family welfare. For example, data should regularly be collected not only on the number and the age of children, but also on their school attendance and grades, etc. This would give invaluable information not only on the determinan ts of women's labour force participation, but also on variability of school attendance. We should know how many months per year a woman works, how many years of working experience she has, her labour force participation history, when she entered work, when she left, when she re-entered, etc. We should know the physical relation between the home and the work place, in terms not only of distance between them but also type of work place, ie, the home itself, or someone else's home, a workshop, factory, etc. This type of information should be permanently collected. Data on the age and sex of relatives living in the same household as the respondent; occupation, income of the husbands of all women living in the same household, should be collected from time to time.

Censuses in Latin America in general have been shown to be poor instruments for capturing labour force participation of both men and women, but the underestimation is much more acute in the case of women, particularly agricultural workers, and unpaid family workers. This can be seen from the very low percentage of women in the economically active population in agriculture in Andean countries: Bolivia (1976) 11.3 per cent; Chile (1970) 3.3 per cent; Colombia (1973) 3.04 per cent; Ecuador (1974) 4.5 per cent; Peru (1972) 9.4 per cent and Venezuela (1977) 6.4 per cent. Both the census and the household survey are able to measure labour participation with greater accuracy in the modern sector and in urban areas, mainly for men but also to a lesser degree for women. But given that Latin America is part of the Third World the vast majority of the Latin American population does not work in this sector. These countries are thus characterised by economic heterogeneity, with the vast majority of the population living in the rural area; and those who do live in the urban areas are involved to a greater degree in the informal than the formal sector.

The question of the underestimation of both men and women's labour force participation and means to overcome it is of more than academic interest. Governments base their plans for economic growth, their employment and wage policies, development policies, housing policies etc, on census data, and if these data contain a wide margin of error the plans can either have limited effectiveness or produce results which are the opposite of those anticipated, or in the worst of cases, can fail utterly.

\section{Conceptual Problems}

Up to this point we have looked merely at the problems of measurement. Now I want to turn to the second and possibly more intractible problem: that of the conceptual frame.

Although it is explicitly stated that the census does not limit itself to activity which receives a money income, in reality it appears that it does limit itself to wage work since it is very poor at capturing unpaid economic activity. Thus economic activity comes to mean only that type of activity that produces a commodity which is then exchanged in the market and to which a price is given. The concept work therefore becomes de facto wage labour or productive work. In contrast, if we define work in terms of the contribution that the activity makes to the survival of the family group, we are no longer merely talking of wage work or productive work but of productive/reproductive work. We must then talk not only of the selling of labour power but also of reproducing labour power. Taking into account this new concept of work, the production and reproduction of the household unit and not merely of the individual, we can classify economic activity as follows [see Rey de Marulanda 1979]:

Those activities which generate income for the individual, which is used for the survival of the family.

Those activities which do not generate an individual income but which serve to support the household as a unit - such as picking coffee - and which may generate part of the household unit's income.

Domestic labour activities which reproduce, daily, generationally or biologically, the household unit. 
Bearing in mind this new way of conceptualising the issue, it is clear that specific and more detailed measurement than can be derived from either the census or the survey is needed.

Since women's participation in agricultural work is one of the areas which is most difficult to capture in both the census and household surveys, let us take it as an example [see Deere and Leon de Leal 1982]. Measurement of women's labour force participation in agriculture is sensitive to the range of activities included as part of agricultural production. The broadest definition of agricultural production includes all the activities connected with crop and animal production, irrespective of whether the final product contributes to use values for family consumption (subsistence production) or exchange values sold in the market (commodity production).

Activities associated with crop production include:

- tasks required to produce or reproduce the means of production (making tools, repairing tools, collection of inputs such as fertiliser, etc);

- fieldwork tasks (plot preparation, planting, weeding, cultivation and harvesting);

- services associated with fieldwork such as cooking for field hands;

- agricultural product transformation or processing (curing tobacco, threshing grains, husking corn);

- tasks involving transport, storage and marketing;

- tasks associated with organising agricultural work and decision making.

In most conventional data collection methods only fieldwork (ie cultivation) is categorised as agricultural work, particularly where fieldwork is associated with exchange values (ie produced for the market and not for consumption). As a result, most of the tasks in which women are involved are not taken into account. These include services associated with agricultural production, fieldwork for subsistence production, processing activities which take place in the home (such as husking corn, drying coffee and animal husbandry).

Women's labour force participation is also sensitive to the way in which participation in the specific range of activities is measured. Measurement possibilities range from respondent evaluation (ie recall) to actual participation, ie time allocation. The associated forms used to measure participation are asking for respondent's occupation; designation of involvement in activity as primary and secondary; subjective evaluation of the frequency or intensity of participation in a given activity: this takes the form of asking whether the person always, sometimes, or never, performs a particular task; indication of the amount of time actually dedicated to a given task within a stated period.

All recall methods suffer from a number of disadvantages. A critical matter is the time frame of the analysis. As a general rule, the smaller the unit of time, the better. However, in agricultural work difficulties are encountered if a small time unit is used because of seasonal activities and the varying intensity of the activity for different household members at different periods of time. Secondly, recall is more accurate when the respondent is the principal person charged with the activity. However, this too is problematic as far as women's participation is concerned, given that women usually 'help out' in activities and are thus frequently left out of account.

Subjective evaluation presents fewer problems. The respondent intuitively knows where to locate $\mathrm{him} /$ herself in terms of sometimes, always, never, doing the activity. It is an easier question to handle for the interviewer with minimum training. It is also useful for capturing the extent of 'helping out' when the woman is not the main person in charge of an activity, and is to be recommended for survey use. In a recent project conducted in Colombia through a sample survey of rural households, where the subjective evaluation question was used, the results for women's participation in agricultural work (bearing in mind the broad definition of agricultural tasks outlined earlier) showed, in contrast to census data which recorded only a 4 per cent labour force participation rate, 45 per cent participation of women in one region, and 56 per cent in another.

The question of the amount of time actually spent in a given activity presupposes previous participant observation of each person within the household, each task, each crop, each plot. It is therefore only to be recommended when the principal researcher is the data collector. It is thus not useful for surveys.

Time allocation is the most accurate measure; it involves a day by day accounting of each task that each member of the household participates in. But it is a very expensive and time consuming method, and furthermore there are problems of generalising from the very few households which can be studied in this way. 


\section{Conclusion}

Anyone who has tried to work with census data, particularly if they are trying to analyse women's participation either nowadays or historically, has probably come up against many of the difficulties touched on in this brief presentation. This not only requires that work relying on uncritical use of such data has to be treated with reserve, but, more importantly, that support must be given by the academic and, particularly, by the research community to attempts to improve basic data conceptualisation and collection.

\section{Acknowledgement}

This article is largely based on work by Wainerman and Recchini de Lates.

\section{References}

Deere, Carmen Diana and Magdalena Leon de Leal, 1982, Women in Andean Agriculture, ILO, Geneva

Leon de Leal, Magdalena, 1980, Mujer y Capitalismo Agrario, ACEP, Bogotá

Rey de Marulanda, Nohora, 1979, 'Diferentes apreciaciones sobre el ama de casa en la sociedad capitalista; CEDE document 058m Bogotá, June

Wainerman, Catalina, H., (with Zulma Recchini de Lates) 1981, Trabajo Femenino en el Banquillo de los Acusados, Population Council and Terra Nova, Mexico 